
\title{
3 Research Square \\ The effect of support surface and footwear condition on postural sway and lower limb muscle action of the old people
}

\section{Meizhen Huang}

Hong Kong Polytechnic University https://orcid.org/0000-0002-4009-7332

Kit-lun Yick ( $\nabla$ kit-lun.yick@polyu.edu.hk)

https://orcid.org/0000-0002-9043-1781

\section{Sun-pui $\mathrm{Ng}$}

Hong Kong Polytechnic University

Joanne Yip

Hong Kong Polytechnic University

Roy Cheung

Hong Kong Polytechnic University

Research article

Keywords: balance, aging, footwear

Posted Date: June 13th, 2019

DOI: https://doi.org/10.21203/rs.2.10274/v1

License: (c) (1) This work is licensed under a Creative Commons Attribution 4.0 International License. Read Full License 


\section{Abstract}

Background: Diminished somatosensory function and lower plantar cutaneous sensitivity have been identified as a critical age-related change, which is related to postural instability in the older population. Footwear is suggested that can modulate the postural stability by altering the interface between the foot sole and the ground. However, it is unclear whether this footwear effect could also influence lower limb muscle activation for the elderly. This study aimed to investigate the footwear insole texture and supporting surface condition on static postural stability and lower limb muscle activation for healthy older people. Methods: This is a single-session study with repeated measurements. Twenty-three healthy older female stood on the firm (i.e., concrete floor) and foam surfaces with their eyes open in the three footwear conditions, namely barefoot, plain shoes and nodulous insole shoes, for 30 seconds. Static postural sway and muscle activation of biceps femoris (BF), vastus lateralis (VL), tibialis anterior (TA), and lateral gastrocnemius (LG) of the dominant leg were measured during each testing condition. Results: compared to firm surface, standing on the foam could significantly increase the body sway and lower limb muscle activation ( $p<0.05$ ); compared to barefoot, when standing on the foam, wearing footwear significantly decreased the VL and TA muscle activation and minimize the postural sway in ML and AP direction, while the influence is larger for the nodulous shoes compared to the plain shoes. A positive correlation was observed between the lower limb muscle activation and AP ( $r=0.327-0.389$, $p<0.001)$ and total sway path length $(r=0.317-0.427, p<0.001)$. Conclusions: footwear could improve the postural stability and decease the fall risk comparing to barefoot when the somatosensory input is in disturbance, while the improvement is larger when wearing nodulous insole footwear for the elderly.

\section{Background}

Balance is often deteriorated with advancing age [1]. The decline in postural stability in older adults increases the risk of falls, which ultimately elevate the morbidity, mortality, and cost of health care services for the elderly [2]. To maintain the normal static bipedal stance, the proprioceptive and cutaneous sensory play a major role [3]. However, diminished somatosensory function and lower plantar cutaneous sensitivity have also been identified as a critical age-related change [4], which is related to postural instability in the older population.

Recent research suggests that footwear can modulate the postural stability by altering the interface between the foot sole and the ground [5]. Though Palluel et al. suggested that spiked insole may enhance static balance [6], other studies failed to find the influence of insole texture characteristics to promote static balance for both young and old adults $[7,8]$. This inconsistency can be due to the ceiling effect related to the testing condition. As the healthy participants could achieve their best performance on a firm surface $[7,9]$, it may not be sufficiently discriminative to detect the change of postural sway across footwear conditions. Indeed, textured insole was reported to reduce the postural sway when standing on foam, when compared to the barefoot condition $[9,10]$. The proposed mechanism of this improvement may be attributed to the enhanced proprioceptive feedback by increased tactile stimulation of the plantar surface of the foot [5]. However, it is unclear whether this footwear effect could also influence lower limb 
muscle activation for the elderly. As to our knowledge, no studies have investigated the effect of footwear insole condition on both static postural stability and lower limb muscle activity for older people.

This study, therefore, aimed to investigate the footwear insole texture and supporting surface condition on static postural stability and lower limb muscle activation for healthy older people. It was hypothesized that (1) footwear insole condition, supporting surface condition and their interaction could have an influence on the postural stability and lower limb muscle activation; (2) there could be a correlation between the muscle activation and postural stability.

\section{Methods}

\section{Participants}

Independent community-dwelling old women were recruited through convenient sampling. The inclusion criteria were: (1) aged more than 60; (2) able to follow simple verbal instructions, (3) no history of foot injuries during the past two years. The exclusion criteria included: (1) having any neurological conditions and musculoskeletal problems that might affect balance; (2) having contract or glaucoma. The study was approved by the Human Subjects Ethics Sub-committee of the University. All the participants provided written informed consent before data collection.

\section{Experimental protocols and procedures}

This is a single-session study with repeated measurements. Demographic data were collected by interviewing the participants, and the dominant limb was determined by a ball kicking task [11].

Each participant underwent three different footwear conditions, namely barefoot, plain shoes made of soft terry textiles (13F302, Yeshunag, Zhejiang, China) (Figure 1a), and nodulous insole shoes with medial arch support and silicone protrusions at the metatarsal heads and lateral heel (KE-1300T, ShinEtsu Chemical Co., Ltd.) (Figure 1b), in a randomized sequence.

Participants then were instructed to maintain quiet standing on firm (i.e., concrete floor) and foam surfaces $\left(46.5 \mathrm{~cm}(\mathrm{~L}) \times 46.5 \mathrm{~cm}(\mathrm{~W}) \times 4.5 \mathrm{~cm}(\mathrm{H}) ; 0.0764 \mathrm{~g} / \mathrm{cm}^{3}\right.$, StimUp® Balance Pad, Will Medical, Tokyo, Japan) with their eyes open in the three footwear conditions. Thus, there were six experimental conditions which were carried out in a randomized order. The standing posture was standardized according to the method used in a previous study [7]. In brief, all the participants' feet were $17 \mathrm{~cm}$ apart from the heel center, with the foot progression angle at $14^{\circ}$. They were asked to stand still with their hands by the sides and looking at a stationary visual target (i.e., a red spot $2 \mathrm{~cm}$ in diameter) placed at eye level and 3-m in front of the participants and put equal body weight on each foot. In each condition, participants were tested thrice for 30 seconds and a rest period of one minute was allowed between each condition [7]. Data during the middle 20 seconds were used for analyses. 


\section{Static postural stability}

Static postural sway was measured as the displacement of center of pressure (COP) using in-shoe pressure measurement system (Pedar ${ }^{\circledR}$, Novel GmbH, Munich, Germany) with sampling frequency at 50 $\mathrm{Hz}$ under the dominant foot. The pedar® insole sensor, which was $2 \mathrm{~mm}$ in thickness and fitted in accordance with foot size, was placed underneath the foot. Referring to previous studies [7, 9], the COP parameters included the range of anterior-posterior (AP) and medial-lateral (ML) COP displacement, path length (PL) and the 95\% confidence elliptical area (C95 area).

\section{Electromyography}

The surface EMG signal was captured using an 8-channel wireless EMG system (Clinical DTS, Noraxon USA Inc., AZ, USA) with 16-bit resolution and common-mode rejection ratio > $100 \mathrm{~dB}$. After proper skin preparation, four circular $\mathrm{Ag} / \mathrm{AgCl}$ bipolar electrodes (electrode diameter: $10 \mathrm{~mm}$, inter-electrode distance: $22 \mathrm{~mm}$ ) were placed on the biceps femoris (BF), vastus lateralis $(\mathrm{VL})$, tibialis anterior $(T A)$, and lateral gastrocnemius (LG) of the dominant leg according to the recommendations of Surface EMG for NonInvasive Assessment of Muscles [12]. The raw signals were pre-amplified 1,000 times and sampled at $3,000 \mathrm{~Hz}$ with $500 \mathrm{~Hz}$ low-pass filter. Prior to postural stability test, maximum voluntary contractions (MVC) for each muscle was collected for $5 \mathrm{~s}$ using manual resistance [13] and repeated three times with five minutes rest period in-between each MVC test (Appendix 1).

\section{Data extraction and processing}

The AP and ML COP displacement, COP path length and the 95\% confidence elliptical area (C95 area) parameters were calculated by the inbuilt pressure measurement system (pedar ${ }^{\circledR} /$ expert Software, Novel $\mathrm{GmbH}$, Munich, Germany).

The EMG signals were processed using MyoResearch 3 (Noraxon USA Inc, AZ, USA). All EMG data were filtered using a first-order high-pass Butterworth filter at $10 \mathrm{~Hz}$ with 8-10\% cutoff. The data were then rectified, and the root-mean-square $\left(\mathrm{EMG}_{\mathrm{rms}}\right)$ was calculated in $100 \mathrm{~ms}$ windows during the 20 -second time-window of the static standing trials. For each muscle, the highest $\mathrm{EMG}_{\mathrm{rms}}$ portion of $100 \mathrm{~ms}$ duration from the three MVC trails for each muscle was extracted and averaged, which was then used for normalization of the $\mathrm{EMG}_{\mathrm{rms}}$ value in each testing condition (i.e., $\mathrm{EMG}_{\mathrm{mvc} \%}$ ) [14].

\section{Statistical analysis}

Statistical analyses were conducted using SPSS (version 22, IBM, Armonk, NY). The dependent variable $\left(E M G_{m v c}\right)$ was positively skewed, which determined by the Shapiro-Wilk test and probability-probability plot. Thus, log transformation was applied to the data to obtain normally distributed responses [15]. 
To test the first hypothesis, two-way repeated measures ANOVA (within-subject factors: three footwear conditions, two supporting surface conditions) was applied to each static stability and EMG variables. Greenhouse-Geisser epsilon adjustment was used when the sphericity assumption was violated. Post-hoc analysis using paired-t-test with Bonferroni adjustment was performed if any overall significant results were identified. The effect size was expressed as partial eta squared $\left(\eta_{p}^{2}\right)[16]$.

To test the second hypothesis, the Pearson correlation was applied between the lower limb muscles activation and static postural stability for the firm and foam surface, respectively.

A significance level of $p \leq 0.05$ was set for two-way repeated ANOVA models, and a more stringent significance level of $p \leq 0.01$ was set for the correlation analysis.

\section{Results}

Twenty-three old women (mean age: $65.1 \pm 3.3$ years) completed all the tests. The demographics are summarized in Table 1.

Significant footwear condition $\times$ supporting surface condition was observed for $V L E M G_{m v c}(p<0.001$, $\left.\eta_{p}{ }^{2}=0.308\right), T A E M G_{m c \%}\left(p=0.002, \eta_{p}{ }^{2}=0.250\right)$, AP displacement $\left(p=0.002, \eta_{p}{ }^{2}=0.249\right)$, COP path length $\left(p=0.005, \eta_{p}{ }^{2}=0.211\right), 95 \%$ confidence elliptical area $\left(p=0.013, \eta_{p}{ }^{2}=0.179\right)$, which indicates positive interaction effects.

\section{Effect of supporting surface condition}

Significant effects of supporting surface were observed for all the postural stability and EMG variables $\left(p<0.05, \eta_{p}{ }^{2}=0.150-0.775\right)$, with significant larger all postural sway parameters and $E M G_{m v c \%}$ was observed when standing on the foam.

\section{Effect of footwear conditions}

A significant effect of the footwear was observed in foam but not the firm surface for $V L E M G_{m v c}$ $\left(p<0.001, \eta_{p}{ }^{2}=0.723\right), T A E M G_{m c} \%\left(p=0.047, \eta_{p}{ }^{2}=0.101\right)$, AP displacement $\left(p=0.03, \eta_{p}{ }^{2}=0.267\right), M L$ displacement $\left(p=0.03, n_{p}^{2}=0.271\right), C 95$ area $\left(p=0.002, n_{p}^{2}=0.254\right)$. Post-hoc analysis showed that the smallest value was observed with nodulous shoes, and highest value was in barefoot $(p<0.05)$ (Figure 2 \& $3)$.

\section{Correlation between muscle activation and postural stability}

In the firm supporting surface, a significant positive correlation was observed between all measured lower limb muscle activation and AP $(r=0.304-0.510, p<0.001)$ or path length $(r=0.260-0.390, p<0.01)$. In the 
foam surface condition, a significant positive correlation was observed between VL or TA muscle activation and AP ( $r=0.327-0.389, p<0.001)$ or path length $(r=0.317-0.427, p<0.001)$ (Table 2).

\section{Discussion}

To our knowledge, this is the first study that investigates the footwear condition and supporting surface conditions on static postural stability and lower limb muscle activation for healthy older people. The key finding of this study indicates that (1) compared to firm surface, standing on the foam could significantly increase the body sway and lower limb muscle activation; (2) compared to barefoot, when standing on the foam, wearing footwear could decrease the lower limb muscle activation and minimize the postural sway in $\mathrm{ML}$ and AP direction, while the influence is larger for the nodulous shoes compared to the plain shoes; (3) positive correlation was observed between the lower limb muscle activation and static postural parameters.

In agreement with the previous study that compared to the firm surface, standing on the foam surface increase the postural sway [9], particular the AP. Meanwhile, the effect of footwear condition on the postural sway [9] was only observed on the foam surface, not the firm surface [7]. When standing on a foam surface, the accuracy of the somatosensory is believed to be affected as the information from the plantar cutaneous mechanoreceptors is disturbed [17]. The AP sway was significantly decreased when wearing both shoes, while ML sway was significantly reduced when with the nodulous shoes (Figure 3 ). Footwear has been suggested to increased tactile stimulation of the sole of the foot [5], and other research has suggested that the spike insole texture could further enhance the plantar cutaneous mechanoreceptors [6], particularly for the elderly who have impaired sensory system [4]. Moreover, footwear is also suggested as a filter for the pressure input to the sole [18], which may remove the disturbance information during standing on the foam. For the elderly, the decline of lateral stability is believed to be closely related to the increased risk of falling [19]. Thus, collectively, compared to barefoot, footwear could improve the postural stability and decease the fall risk when the somatosensory input is in disturbance, while the improvement is larger when wearing nodulous insole footwear for the elderly.

This study found that the lower-limb muscle activation was affected by the footwear condition only in the foam surface, but not the firm surface condition, which partly coincides with the findings of the young healthy population that the lower limb muscle activity was not affected by the footwear as testing on the firm surface [7]. Similar to a previous report, the lower limb muscle activity significantly increased when standing on the foam surface than the firm surface, which may be due to the corrective postural activity [20].

One interesting finding of the present study is that footwear could significantly decrease muscle activity for the vastus lateralis and tibial anterior muscle but not other tested muscles, while the significant correlation was only observed for these two muscles with postural sway parameters. Standing on an unstable supporting surface largely challenge the stability of knee joint [20] and subtalar joint [21]. Tibial anterior, the major foot inverter muscles, activate with other extrinsic and intrinsic foot muscles to 
maintain proper foot alignment [21]. Thus, in consistent with previous findings, standing on the foam significantly increase the TA muscle activation [20,22], while the gastrocnemius muscle activity was only partially corresponding to the body sway [22]. Footwear, on the other hand, creating a relatively stable support for lower limb alignment, which can offload the muscle activation of TA and VL. Furthermore, as the measured muscle is not involved in lateral stability control, the activity of measured muscles was not related to the ML sway [10].

This study acknowledges a few limitations. First, only old women were involved in this study. The previous study suggested that the gender difference might exist in balance control and somatosensory function for the healthy elderly [23], thus recruiting the same gender in this study could minimize the potential confounding factors. However, future study should examine both male and female participants. Second, only muscle activation and COP changes in the dominant foot were measured. In this study, the participants were instructed to maintain equal body weight between two feet. Thus, the measurement in the dominant side could represent the performance of the lower limb. Third, the foam surface was used in this study. Although standing on foam does not imitate a real-life situation commonly encountered by older adults [9], this condition better represents floor surface the elderly encounter in daily life and provides more information on the effect of footwear to balance control as the somatosensory information is challenged.

\section{Conclusion}

Standing on foam could significantly increase the body sway and lower limb muscle activation. When standing on the foam surface, wearing footwear could decrease the lower limb muscle activation and minimize the postural sway comparing to the barefoot, while the influence is larger for the nodulous insole footwear compared to the plain insole. For the older people, footwear could improve the postural stability and decrease the fall risk when the somatosensory input is in disturbance, while the improvement is larger when wearing nodulous insole footwear for the elderly.

\section{List Of Abbreviations}




\begin{tabular}{ll} 
AP & Anterior-posterior \\
\hline EMG & Electromyography \\
\hline RMS & Root-mean-square \\
\hline BF & Biceps femoris \\
\hline C95 area & 95\% confidence elliptical area \\
\hline COP & Center of pressure \\
\hline LG & Lateral gastrocnemius \\
\hline ML & Medial-lateral \\
\hline MVC & Maximum voluntary contractions \\
\hline TA & Tibialis anterior \\
\hline VL & Vastus lateralis
\end{tabular}

\section{Declarations}

Ethics approval and consent to participate

This study was approved by the Human Subjects Ethics Sub-committee of The Hong Kong Polytechnic University (Reference Number: HSEARS20150806001). All procedures performed in studies involving human participants were in accordance with the ethical standards of the institutional and/or national research committee and with the 1964 Helsinki declaration and its later amendments or comparable ethical standards. Informed consent was obtained from all individual participants included in the study.

\section{Consent for publication}

Not application.

\section{Availability of data and materials}

Please contact the corresponding author for the data request.

\section{Competing interests}

The authors declare that they have no competing interests. 


\section{Funding}

The work is supported by funding from the Innovation and Technology Fund (ITF) (ITS/359/14) and Faculty Research Fund (1-ZVLH).

\section{Authors' contributions}

$\mathrm{KY}, \mathrm{SN}, \mathrm{JP}$ and RC conceived and planned the experiments. KY, SN and JP carried out the experiments. $\mathrm{MH}, \mathrm{KY}$ and $\mathrm{RC}$ contributed to the interpretation of the results. $\mathrm{MH}$ took the lead in writing the manuscript. All authors provided critical feedback and helped shape the research, analysis, and manuscript. All authors read and approved the final manuscript.

\section{References}

1. Seidler RD, Bernard JA, Burutolu TB, Fling BW, Gordon MT, Gwin JT, Kwak Y, Lipps DB: Motor control and aging: links to age-related brain structural, functional, and biochemical effects. Neuroscience \& Biobehavioral Reviews 2010, 34(5):721-733.

2. Rubenstein LZ: Falls in older people: epidemiology, risk factors and strategies for prevention. Age and ageing 2006, 35(suppl_2):ii37-ii41.

3. Bacsi AM, Colebatch JG: Evidence for reflex and perceptual vestibular contributions to postural control. Experimental brain research 2005, 160(1):22-28.

4. Shaffer SW, Harrison AL: Aging of the somatosensory system: a translational perspective. Physical therapy 2007, 87(2):193-207.

5. Aboutorabi A, Bahramizadeh M, Arazpour M, Fadayevatan R, Farahmand F, Curran S, Hutchins SW: A systematic review of the effect of foot orthoses and shoe characteristics on balance in healthy older subjects. Prosthetics and orthotics international 2016, 40(2):170-181.

6. Palluel E, Nougier V, Olivier I: Do spike insoles enhance postural stability and plantar-surface cutaneous sensitivity in the elderly? Age 2008, 30(1):53-61.

7. Hatton AL, Dixon J, Martin D, Rome K: The effect of textured surfaces on postural stability and lower limb muscle activity. Journal of Electromyography and Kinesiology 2009, 19(5):957-964.

8. Brenton-Rule A, D'Almeida S, Bassett S, Carroll M, Dalbeth N, Rome K: The effects of sandals on postural stability in patients with rheumatoid arthritis: an exploratory study. Clinical Biomechanics 2014, 29(3):350-353.

9. Qiu F, Cole MH, Davids KW, Hennig EM, Silburn PA, Netscher H, Kerr GK: Enhanced somatosensory information decreases postural sway in older people. Gait \& Posture 2012, 35(4):630-635. 
10. Hatton AL, Dixon J, Rome K, Martin D: Standing on textured surfaces: effects on standing balance in healthy older adults. Age Ageing 2011, 40(3):363-368.

11. Hoffman M, Schrader J, Applegate T, Koceja D: Unilateral postural control of the functionally dominant and nondominant extremities of healthy subjects. $J$ Athl Train 1998, 33(4):319-322.

12. Hermens HJ, Freriks B, Merletti R, Stegeman D, Blok J, Rau G, Disselhorst-Klug C, Hägg G: European recommendations for surface electromyography. Roessingh research and development 1999, 8(2):13-54.

13. Murley GS, Landorf KB, Menz HB, Bird AR: Effect of foot posture, foot orthoses and footwear on lower limb muscle activity during walking and running: a systematic review. Gait \& posture 2009, 29(2):172187.

14. Huang M, Pang MYC: Muscle activity and vibration transmissibility during whole-body vibration in chronic stroke. Scand J Med Sci Sports 2019, 0(0).

15. Manning WG, Mullahy J: Estimating log models: to transform or not to transform? Journal of health economics 2001, 20(4):461-494.

16. Fritz CO, Morris PE, Richler JJ: Effect size estimates: current use, calculations, and interpretation. Journal of Experimental Psychology: General 2012, 141(1):2.

17. Wu G, Chiang J-H: The significance of somatosensory stimulations to the human foot in the control of postural reflexes. Experimental brain research 1997, 114(1):163-169.

18. Nigg BM: The role of impact forces and foot pronation: a new paradigm. Clinical journal of sport medicine 2001, 11(1):2-9.

19. Melzer I, Benjuya N, Kaplanski J: Postural stability in the elderly: a comparison between fallers and non-fallers. Age and ageing 2004, 33(6):602-607.

20. Fransson P-A, Gomez S, Patel M, Johansson L: Changes in multi-segmented body movements and EMG activity while standing on firm and foam support surfaces. European journal of applied physiology 2007, 101(1):81-89.

21. Landry SC, Nigg BM, Tecante KE: Standing in an unstable shoe increases postural sway and muscle activity of selected smaller extrinsic foot muscles. Gait \& posture 2010, 32(2):215-219.

22. Loram ID, Maganaris CN, Lakie M: Paradoxical muscle movement during postural control. Medicine \& science in sports \& exercise 2009, 41(1):198-204.

23. Wolfson L, Whipple R, Derby CA, Amerman P, Nashner L: Gender differences in the balance of healthy elderly as demonstrated by dynamic posturography. Journal of Gerontology 1994, 49(4):M160-M167. 


\section{Tables}

Table 1. Demographic data of the participants

\begin{tabular}{lcc}
\hline Demographic data & Range & Mean (SD) \\
\hline Age (years) & $60.0-73.0$ & $65.1(3.3)$ \\
Body height $(\mathrm{m})$ & $1.42-1.66$ & $1.54(0.55)$ \\
Body mass $(\mathrm{kg})$ & $38.0-65.0$ & $51.7(6.3)$ \\
BMI $\left(\mathrm{kg} / \mathrm{m}^{2}\right)$ & $15.2-32.2$ & $22.2(3.4)$ \\
Foot size (Euro) & $35-40$ & $37.4(1.1)$ \\
Dominant foot & Right $(\mathrm{n}=20) ;$ Left $(\mathrm{n}=0)$ \\
\hline
\end{tabular}

Table 2. Correlation between the muscle activation and postural sway

\begin{tabular}{cccccc}
\hline & & VL & BF & LG & TA \\
\hline $\begin{array}{c}\text { Firm } \\
\text { surface }\end{array}$ & AP & $0.304^{* *}$ & $0.383^{* *}$ & $0.365^{* *}$ & $0.510^{* *}$ \\
& Path length & $0.260^{*}$ & $0.304^{* *}$ & $0.490^{* *}$ & $0.390^{* *}$ \\
& & & & & \\
Foam surface & AP & $0.389^{* *}$ & NS & NS & $0.327^{* *}$ \\
& Path length & $0.427^{* *}$ & NS & NS & $0.317^{* *}$ \\
\hline
\end{tabular}

AP: anterior-posterior displacement; BF: biceps femoris; LG: lateral gastrocnemius; TA: tibial anterior; VL: vastus lateralis; NS: no significance

$* \mathrm{p}<0.01$

$* * \mathrm{p}<0.001$

Figures 
a

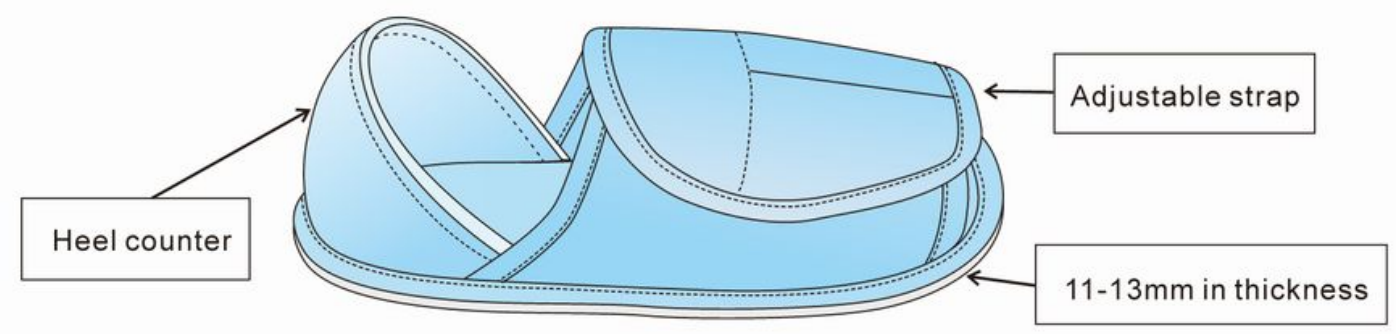

b
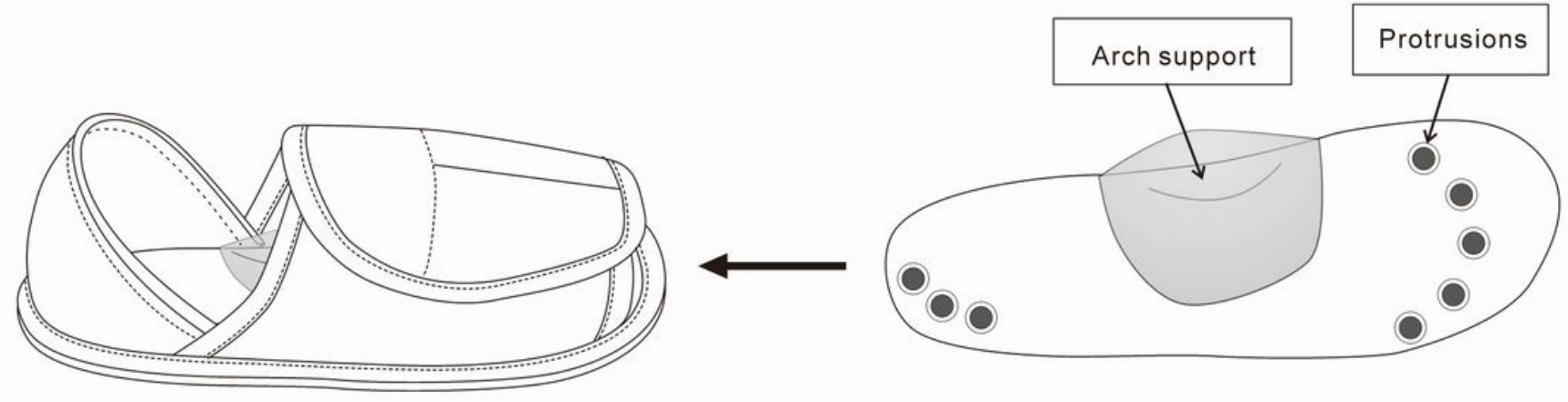

\section{Figure 1}

Test shoe models (a) The plain shoes are open-toe design with secured heel counter and an adjustable dorsal forefoot strap. The sole thickness is uniform across the plantar; (b) The nodulous shoes is the same plain shoes with raised nodulous and medial arch support.
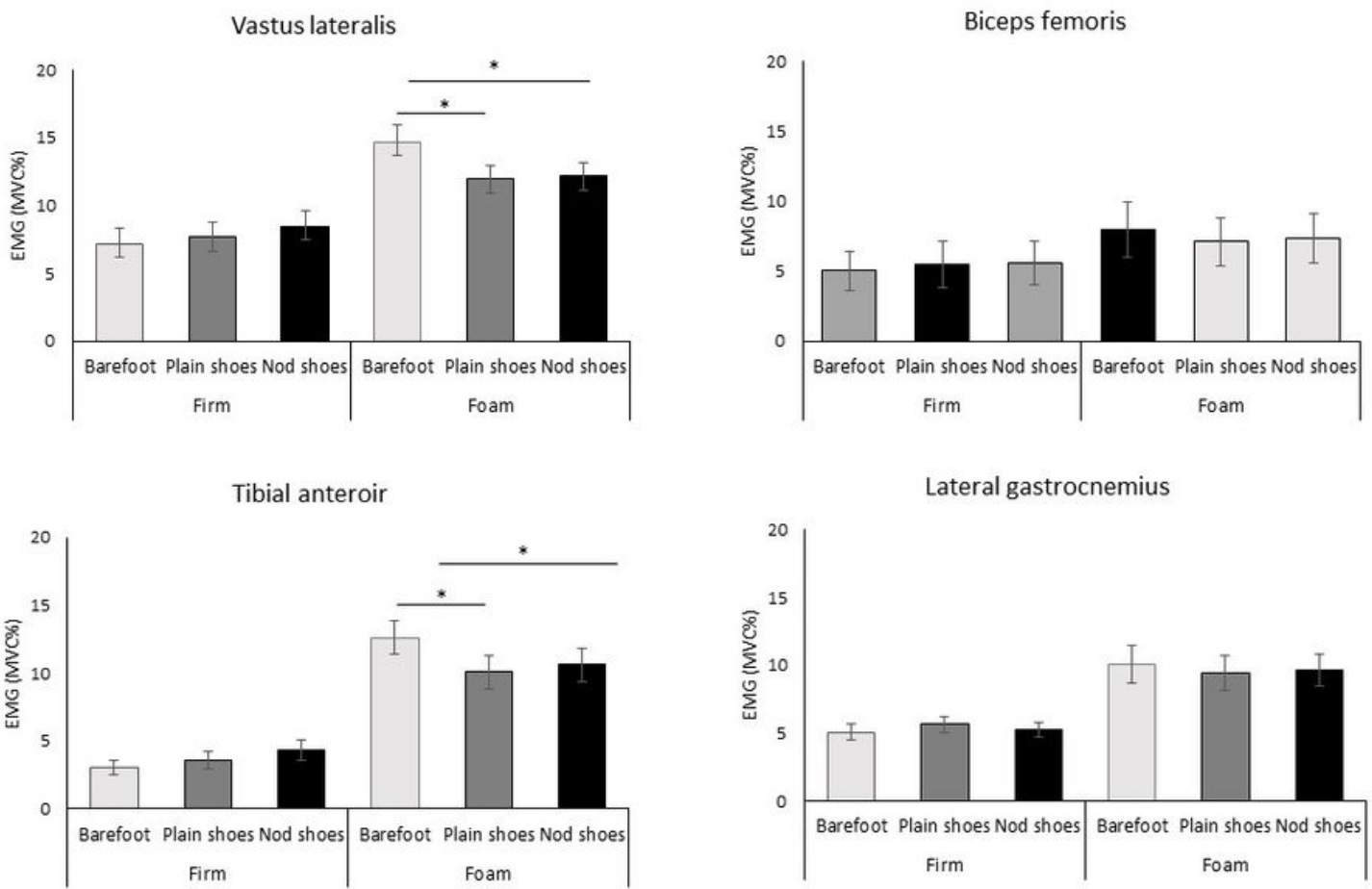
Figure 2

Lower limb muscle activity. Nod shoes: nodulous shoes. * Significant difference of pair-t test, $p<0.05$ with Bonferroni adjustment
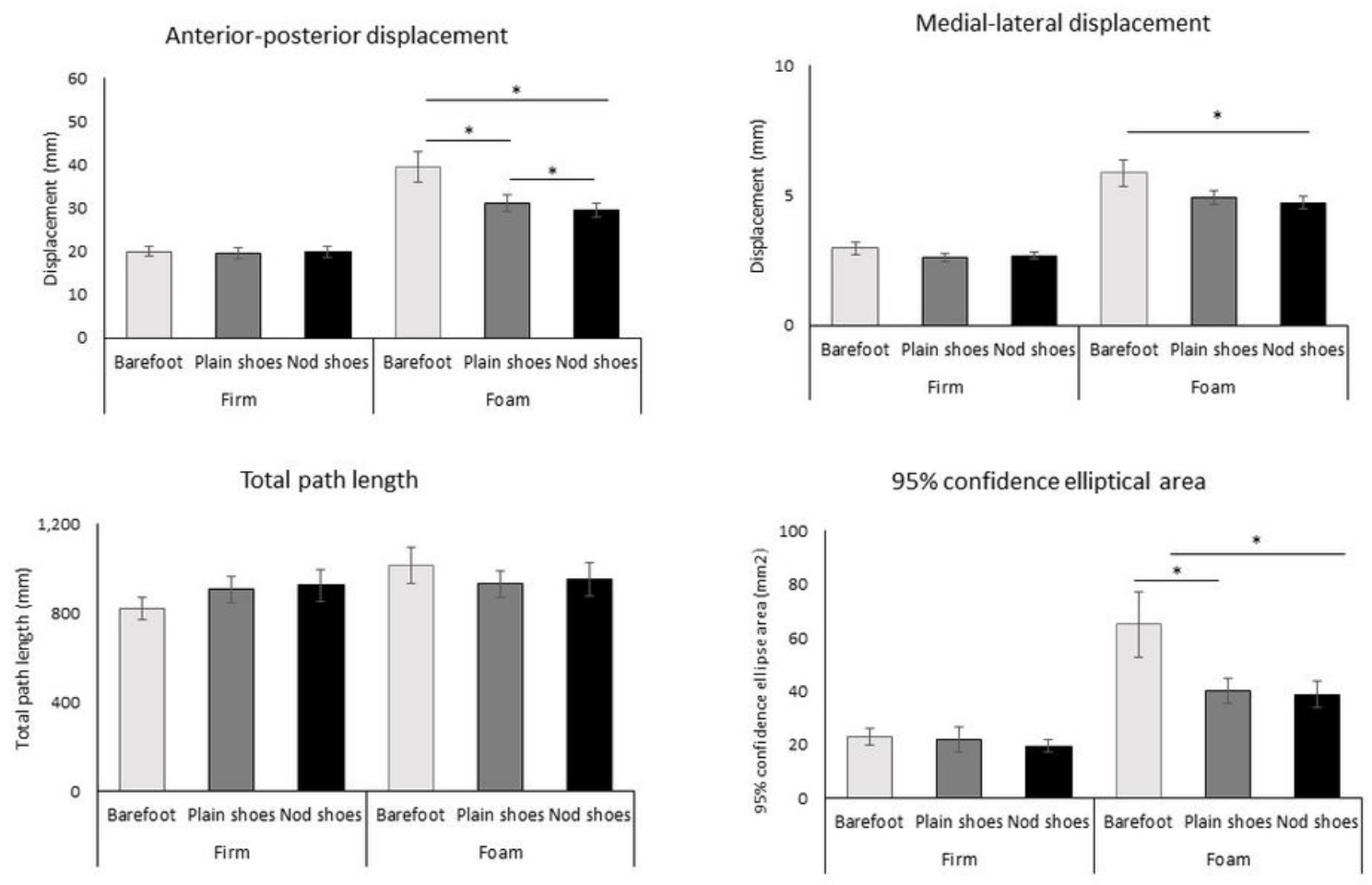

\section{Figure 3}

Postural sway Nod shoes: nodulous shoes. * Significant difference of pair-t test, $p<0.05$ with Bonferroni adjustment

\section{Supplementary Files}

This is a list of supplementary files associated with this preprint. Click to download.

- Appedix1MVC.docx 